\title{
A Simple Model to Calculate Dendrite Growth Rate during Steel Continuous Casting Process
}

\author{
Mujun LONG, ${ }^{1)}$ Lifeng ZHANG, ${ }^{2)}$ and Fei LU ${ }^{31}$ \\ 1) Visiting Scholar at Department of Materials Science and Engineering, Missouri University of Science and Technology \\ (Missouri S\&T), USA; Ph.D Student at College of Materials Science and Engineering, Chongqing University, P.R. China. \\ 2) Department of Materials Science and Engineering, Missouri University of Science and Technology (Missouri S\&T), 223 \\ McNutt Hall, Rolla 65409-0330, USA. E-mail: zhanglife@mst.edu $\quad 3)$ Ph.D. Student at Department of Material Science \\ and Engineering, Missouri University of Science and Technology, 223 McNutt Hall, Rolla 65409-0330, USA.
}

(Received on April 13, 2010; accepted on August 5, 2010)

\begin{abstract}
In the current paper, the relationship between the casting speed and the dendrite growth during steel continuous casting process was studied; and a simple mathematical model to calculate the primary dendrite growth rate according to the casting speed was developed. The model was used to predict the distribution of the dendrite growth rate along width direction and casting direction during a continuous casting process, indicating a dendrite growth rate of $0.1-3.0 \mathrm{~mm} / \mathrm{s}$, which is much higher than that in regular ingot casting. The dendrite growth rate fluctuates along casting direction because of the different cooling intensity in each zone of the continuous caster; and the distribution of the dendrite growth rate along width direction was non-uniform due to the uneven transverse distribution of cooling intensity. The predicted results agree well with the measurements.
\end{abstract}

KEY WORDS: dendrite growth rate; steel continuous casting; microstructure; solidification.

\section{Introduction}

Solidification rate and dendrite growth rate are of importance for the product quality in steel continuous casting process. During solidification, dendrites grow as long as there is heat transfer from the molten steel to the strand surface, where the heat is carried away by cooling water. If the dendrite grows too slow, the steel shell is thin that break-out may occur. If the dendrite growth rate is too large, special defects may be generated in the steel product. Thus the flow rate of cooling water is adjusted under different casting speed to guarantee the proper solidification rate, to avoid break-out and overcooling during steel casting process. Extensive studies on the microstructure of casting steel during solidification have been performed. ${ }^{1-6)}$ Imagumbai, ${ }^{7)}$ Chalmers et al., ${ }^{8-10)}$ Byungsoo, ${ }^{11)}$ Okane et al., ${ }^{12)}$ and Yamazaki et al., ${ }^{13)}$ reported that the dendrite growth rate is relative to the temperature gradient ahead of the primary dendrite tip; Imagumbai et al., ${ }^{14)}$ Cicutti et al., ${ }^{15)}$ and Wolf et al., ${ }^{16)}$ assumed the dendrite growth rate to be the growth rate of the shell thickness with time. Both the temperature gradient and the shell thickness depend on the cooling rate during continuous casting process, which is dominated by the casting speed at the cooling conditions. During steel continuous casting, a stronger cooling rate is applied at higher casting speed to guarantee the proper metallurgical length. In the current paper, the relationship between the primary dendrite growth rate and the casting speed was investigated, and a simple model to calculate the dendrite growth rate was developed.

\section{Model of Dendrite Growth Rate Related to Casting Speed}

The primary dendrite growth rate during the steel continuous casting greatly depends on the casting speed, which is different from that during ingot casting process. For a steady state continuous casting, the casting speed has to correspond to a suitable dendrite growth rate. Otherwise, if the dendrite growth rate is so big that the incoming hot metal cannot provide enough heat, which means a too small casting speed, the mold will be finally frozen. If the dendrite growth rate is too small, the incoming hot metal will bring too much heat, which implies a too large casting speed, the solidified shell will be remelted and finally break-out will occur.

The dendrite grows at the dendrite tip in the mushy zone of the strands ${ }^{17)}$; and the orientation of dendrite growth is perpendicular to the isothermal surface of solidus temperature which is the heat flux direction, while the casting speed direction is parallel to the strand moving orientation, as illustrated in Fig. 1. Assuming a steady continuous casting process, the dendrite grows as the strand moves. The dendrite growth rate $(V)$ should be a branch of the casting speed $\left(V_{c}\right)$ as shown in Fig. 1.

The isothermal curves of the liquidus temperature as $f_{L}\left(V_{c}, Z\right)$, and the solidus temperature $f_{S}\left(V_{c}, Z\right)$, can be obtained by calculating the macro-temperature field during solidification of continuous casting process. ${ }^{18,19)}$ If the slopes for the tangential lines of the liquidus temperature curve and the solidus temperature curve are available, the dendrite 


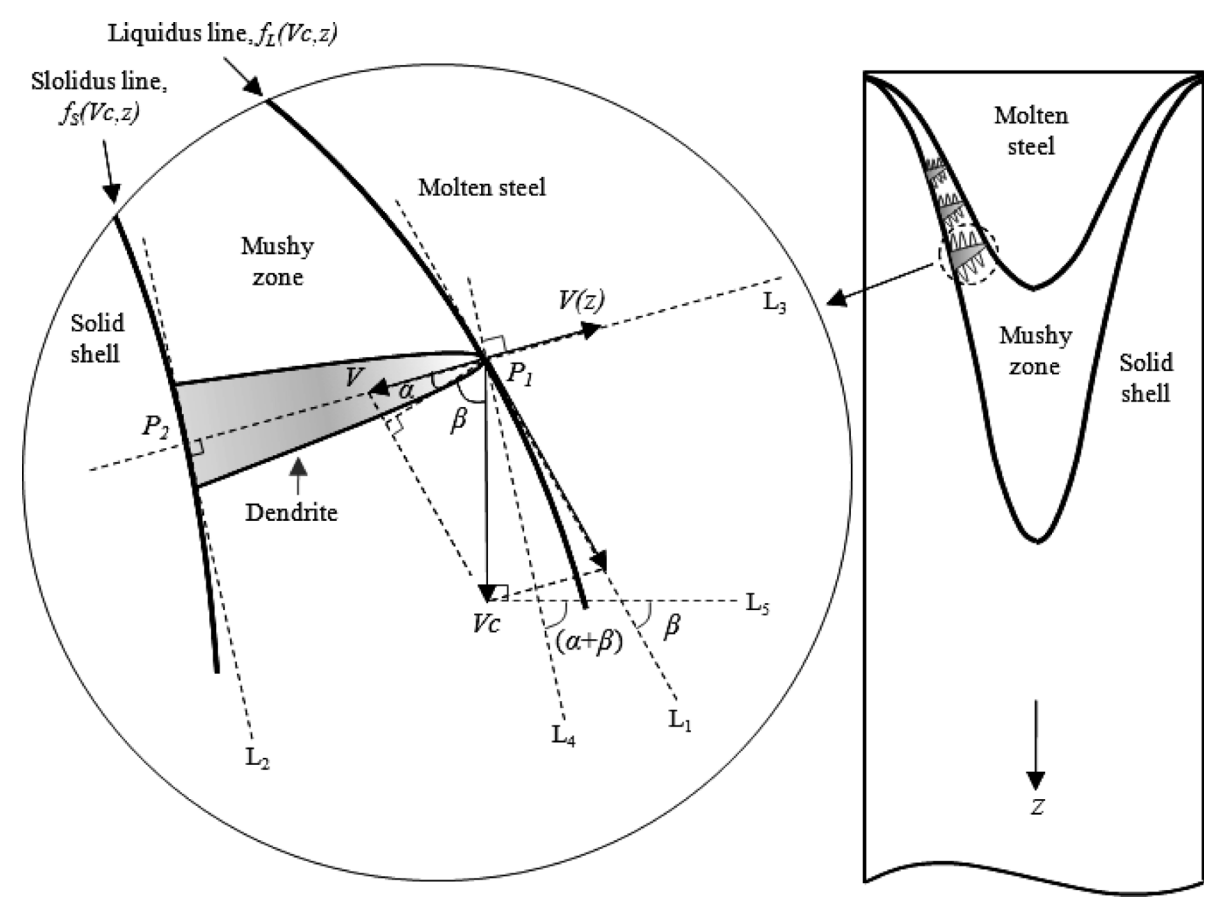

Fig. 1. Schematic of the relationship between dendrite growth rate and casting speed.

growth rate can be calculated.

For the dendrite growth velocity $(V(z))$ at point $P_{1}$, the orientation is along line $\mathrm{L}_{3}$ as shown in Fig. 1, which is perpendicular to the tangent $\left(\mathrm{L}_{2}\right)$ of the solidus line at point $P_{2}$. And line $\mathrm{L}_{1}$ is the tangent of the liquidus line at point $P_{1}$. Line $\mathrm{L}_{4}$ is parallel to line $\mathrm{L}_{2}$. Line $\mathrm{L}_{5}$ is a horizontal line which is perpendicular to the casting direction $\left(V_{c}\right)$.

As indicated in Fig. 1, the relationships between $f_{L}\left(V_{c}, Z\right)$, $f_{S}\left(V_{c}, Z\right)$, angle $\alpha$ and angle $\beta$ can be written as:

$$
\begin{gathered}
\left.\frac{d f_{L}\left(V_{c}, z\right)}{d z}\right|_{\text {point } P_{1}}=\operatorname{ctg} \beta \ldots \ldots \\
\left.\frac{d f_{S}\left(V_{c}, z\right)}{d z}\right|_{\text {point } P_{2}}=\operatorname{ctg}(\alpha+\beta)
\end{gathered}
$$

where $z$ is the distance from the meniscus in meter; $V_{c}$ is the casting speed in $\mathrm{m} / \mathrm{s}$. The relationship between $V_{c}$ and $V(z)$ can be represented as:

$$
\left.V(z)\right|_{\text {point } P_{1}}=V_{c} \cdot \frac{\cos \beta}{\cos \alpha}
$$

According to the Eqs. (1), (2) and (3), $V(z)$ at point $P_{1}$ can be calculated by:

$$
\left.V(z)\right|_{\text {point } P_{1}}=V_{c} \cdot\left\{\frac{\sqrt{1+\left[\left.\frac{d f_{S}\left(V_{c}, z\right)}{d z}\right|_{\text {point } P_{2}}\right]^{2}}}{\left.\frac{d f_{S}\left(V_{c}, z\right)}{d z}\right|_{\text {point } P_{2}}+\frac{1}{\left.\frac{d f_{L}\left(V_{c}, z\right)}{d z}\right|_{\text {point } P_{1}}}}\right\}
$$

As shown in Fig. 1, to calculate the dendrite growth rate at the locations of the dendrite tip $P_{1}$ (at the liquidus tempera-

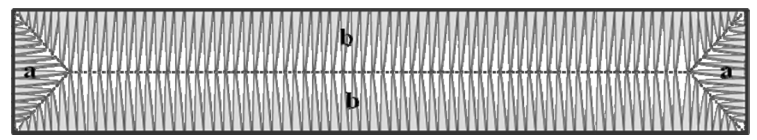

Fig. 2. Schematic of the dendrite growth in the continuous casting strand.

ture line), the corresponding location $P_{2}$ at the solidus temperature line should be obtained first by drawing a normal line $\left(P_{1}-P_{2}\right)$ from the solidus temperature curve. It should be noticed that $P_{1}$ at the liquidus isothermal curve and $P_{2}$ at the solidus isothermal curve are not at the same distance to the meniscus.

In the current paper, the dendrite growth during continuous casting process is simply assumed as in Fig. 2. The dendrite growth at region "a", whose orientation is perpendicular to the narrow surface, was not considered in the current model; instead, it is assumed to be in the same orientation of that at region " $b$ ". However, there is no difference for the complete solidification time since the heat transfer from both narrow surfaces and wide surfaces were taken into account in the heat transfer model. ${ }^{18,19)}$ In the current study, the primary dendrite growth is assumed to stopwith zero dendrite growth rate-after the temperature of molten steel is lower than the liquidus temperature.

\section{Results and Discussion}

\subsection{Solidus Temperature Line and Liquidus Tempera- ture Line}

With the macro-heat transfer and solidification model, ${ }^{18,19)}$ the isothermal curves of the solidus temperature and the liquidus temperature of steel AH36 with a chemical compositions as listed in Table $\mathbf{1}$ during slab continuous casting process can be obtained. The parameters used are shown in Table 2. The variation of liquidus temperature line and solidus temperature line at the slab center along the casting 
Table 1. Composition of steel AH36 in \%mass.

\begin{tabular}{ccccc}
\hline $\mathrm{C}$ & $\mathrm{Mn}$ & $\mathrm{Si}$ & $\mathrm{S}$ & $\mathrm{P}$ \\
\hline$\leq 0.18$ & $0.9-1.60$ & $\leq 0.50$ & $\leq 0.035$ & $\leq 0.035$ \\
\hline
\end{tabular}

Table 2. Parameters for the continuous caster.

\begin{tabular}{cccc}
\hline Steel grade & Dimension & Casting speed & Pouring temperature \\
\hline AH36 & $1400 \mathrm{~mm} \times 170 \mathrm{~mm}$ & $1.25 \mathrm{~m} / \mathrm{min}$ & $1821 \mathrm{~K}$ \\
\hline
\end{tabular}

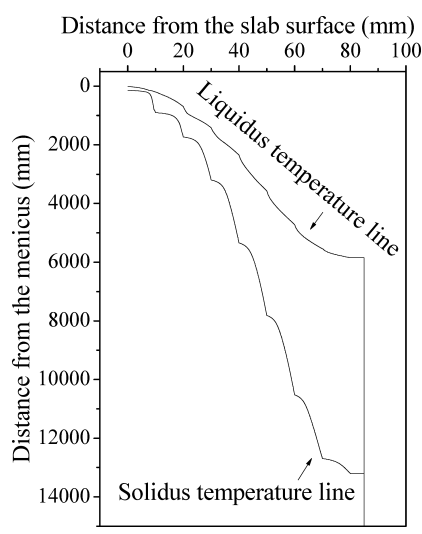

Fig. 3. Variation of the liquidus line and the solidus line at the slab center along the casting direction.

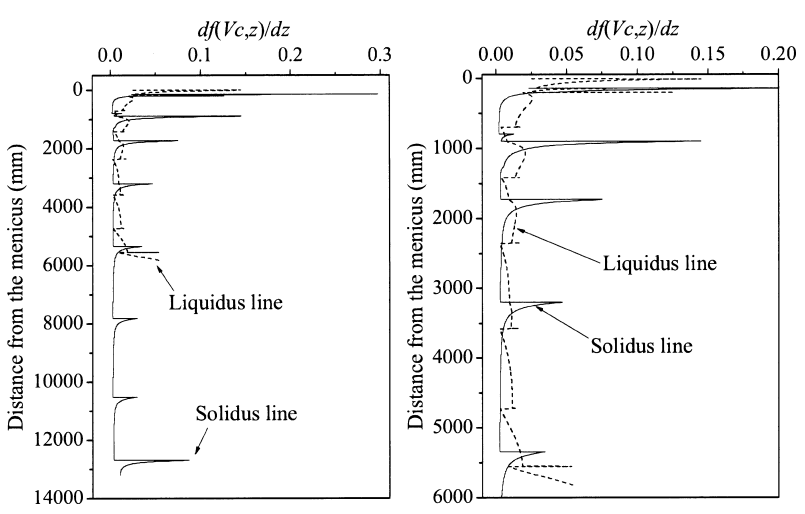

Fig. 4. Differentiation of liquidus line and solidus line along the casting direction.

direction were illustrated in Fig. 3. The waved variation at some locations is due to the change of the cooling condition at different section of the continuous caster. Louhenkilpi reported a similar variation trend of shell thickness. ${ }^{20)}$

Differentiation of the liquidus temperature line and solidus temperature line were illustrated in Fig. 4. At the waved points shown in Fig. 3, the differentiation shows big jumpings which again is induced by the change of the cooling condition of the continuous caster. The change of the cooling condition depends on the difference of water flow rate between the two neighboring sections and the transition of cooling. The jumping is smaller if the transition of cooling condition between the two neighboring sections is better. The unsuitable transition of cooling condition in the continuous caster causes big jumping.

\subsection{Dendrite Growth Rate}

With the current dendrite growth model, the growth rate of the primary dendrite in the slab during continuous casting is predicted. Variation of the dendrite growth rate at dif-
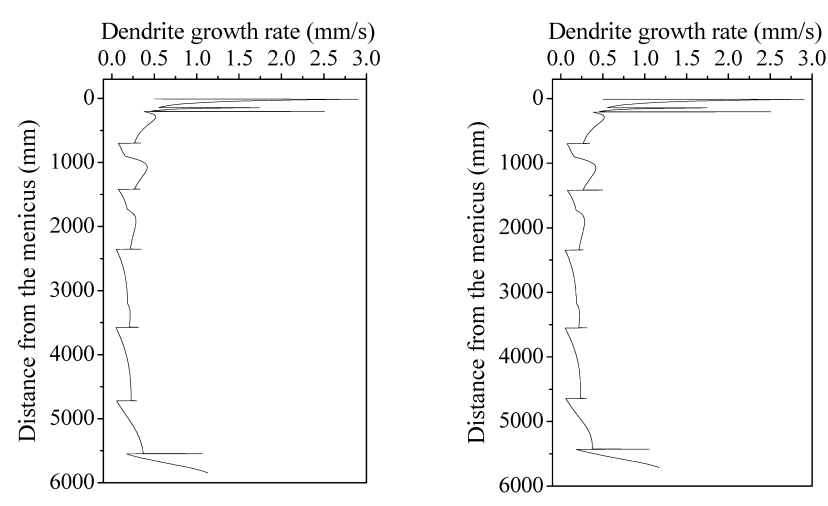

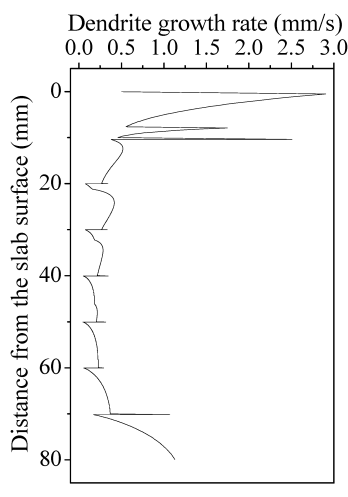

(a) At the slab center

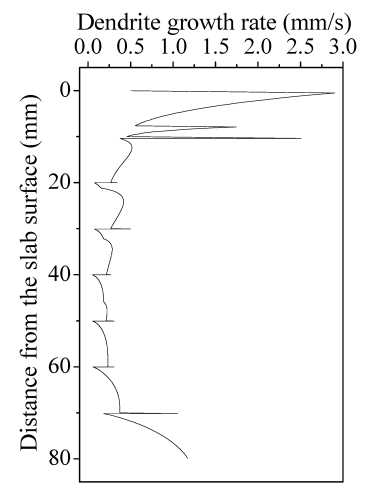

(b) $350 \mathrm{~mm}$ away from the slab center
Fig. 5. Variation of the dendrite growth rate at different locations.

ferent locations is illustrated in Fig. 5. The dendrite growth rate during the current slab continuous casting is $0.05-$ $3.0 \mathrm{~mm} / \mathrm{s}$. The mold has largest dendrite growth rate because of the strong water cooling there. This agrees well with the measurement by Imagumbai, ${ }^{14)}$ who reported that dendrite growth rate during slab continuous casting is $0.148-4.09 \mathrm{~mm} / \mathrm{s}$. The current calculation also agrees well with the simulation by Wolf, ${ }^{16)}$ who reported a value of $0.5-6.0 \mathrm{~mm} / \mathrm{s}$ during continuous casting. Due to the different cooling rates at different zones, the dendrite growth rate at the secondary cooling zone fluctuates a lot; however, the growth rate keeps in the range of $0.05-0.6 \mathrm{~mm} / \mathrm{s}$ except that at the terminal solidification end, where a higher dendrite growth rate exists because of less heat released there. Many researchers ${ }^{7,15,21-23)}$ reported the dendrite growth during continuous casting process (Table 3) that agrees well with the current study. The orientation of the dendrite growth is illustrated in Fig. 6, which is shown as the angle degree between the dendrite growth direction and the casting direction. This angle is in the range of $90-107^{\circ}$.

Figure 7 illustrates the distribution of the dendrite growth rate along the transverse (width) direction at the location of $5.4 \mathrm{~m}$ away from the meniscus, indicating that, the thickness of solid shell is $\sim 100 \mathrm{~mm}$ at the narrow side where the dendrite growth rate is zero; and the highest dendrite growth rate happens at the location $\sim 140 \mathrm{~mm}$ away from the slab narrow surface. The dendrite growth rate at the slab center is a little smaller because of the weaker cooling intensity there.

Figure 8 shows the variation of the dendrite growth rate in the slab along width direction and casting direction during continuous casting process. In the casting mold, the 
ISIJ International, Vol. 50 (2010), No. 12

Table 3. Dendrite growth rate reported by previous researches.

\begin{tabular}{ccccc}
\hline Author & Condition & Dendrite growth rate & Year & Reference \\
\hline Imagumbai & $\begin{array}{c}\text { Steel CC } \\
\text { Experimental measurement }\end{array}$ & $0.148 \mathrm{~mm} / \mathrm{s}-4.09 \mathrm{~mm} / \mathrm{s}$ & 1994 & $1^{14)}$ \\
Wolf & $\begin{array}{c}\text { Steel CC } \\
\text { In the mold }\end{array}$ & $0.5 \mathrm{~mm} / \mathrm{s}-6.0 \mathrm{~mm} / \mathrm{s}$ & 1997 & $1^{16)}$ \\
Kurz & $\begin{array}{c}\text { Steel CC } \\
\text { In the mold }\end{array}$ & $1 \mathrm{~mm} / \mathrm{s}-4 \mathrm{~mm} / \mathrm{s}$ & 2008 & $2^{22)}$ \\
Louhenkilpi & Steel CC & $0.1 \mathrm{~mm} / \mathrm{s}-1.5 \mathrm{~mm} / \mathrm{s}$ & 2003 & 21 21) \\
Kurz & Steel alloy ingot & $0.0018 \mathrm{~mm} / \mathrm{s}-0.3 \mathrm{~mm} / \mathrm{s}$ & 1999 & $24)$ \\
Toshioka & Alloy ingot casting & $0.004 \mathrm{~mm} / \mathrm{s}-0.4 \mathrm{~mm} / \mathrm{s}$ & 2004 & $25)$ \\
\hline
\end{tabular}

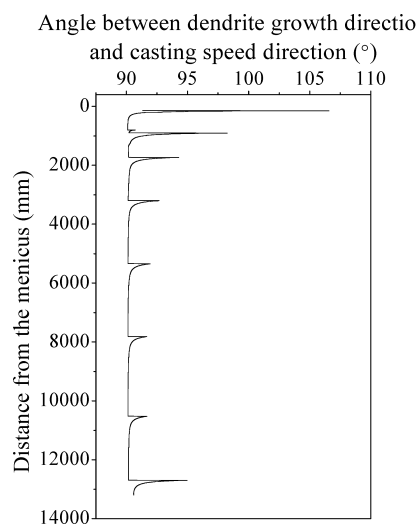

Fig. 6. Orientation of the dendrite growth along the casting direction.

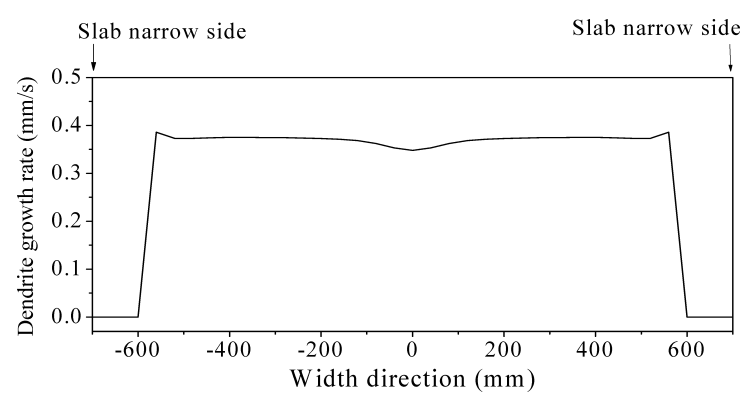

Fig. 7. Distribution of the dendrite growth rate along the width direction at $5.4 \mathrm{~m}$ away from the meniscus.

dendrite growth rate is high due to the strong cooling, thus the dendrites grow faster than other places. Because of the heat transfer from both wide surface and narrow surface, the dendrite growth rate at the slab corner is larger than that at the other part. At the secondary cooling zone, the dendrite growth rate fluctuates as the cooling rate changes. Since the dendrite growth perpendicular to the narrow surface (region "a" in Fig. 2) is not taken into account, the location near the narrow face completely solidifies quickly at $\sim 2 \mathrm{~m}$ away from the meniscus, and thus there is a large peak of the dendrite growth rate there. The dendrite growth rate distributes non-uniformly along the width direction because of the uneven distribution of cooling intensity at the secondary cooling zone, especially at the final stage of solidification.

The dendrite growth rate at the cross section of the slab is plotted in Fig. 9. The result shows again that the dendrite

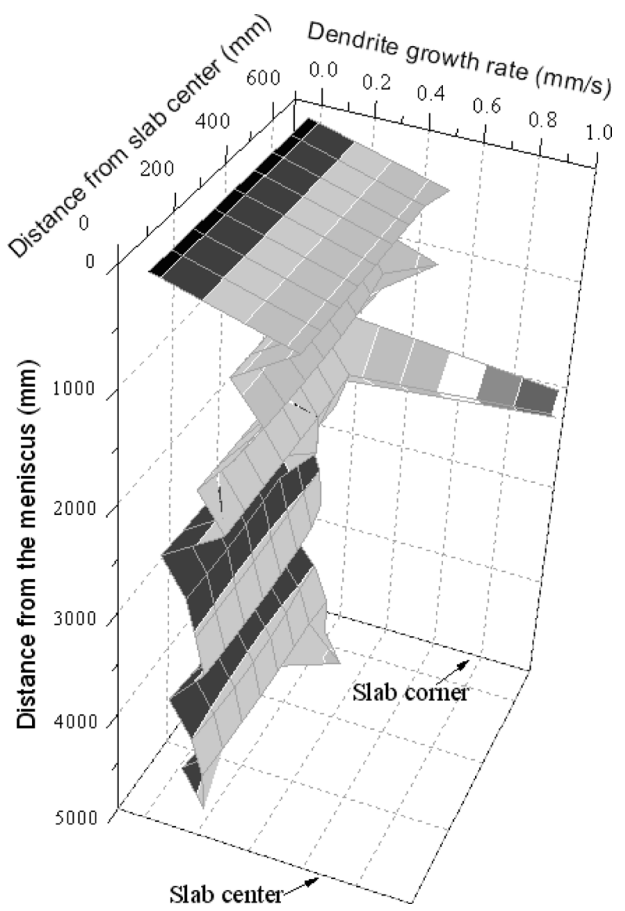

Fig. 8. Variation of the dendrite growth rate in the slab.

growth rate fluctuates as steel solidifies from the slab surface to the slab center due to the diverse cooling intensities at different cooling zones. The locations near the slab surface and slab center (terminal solidification end) have larger dendrite growth rate than other locations. Along the width direction, the dendrite growth rate near the slab narrow sides is more complicated and larger than other locations due to the effect of the heat transfer from the wide surface and the narrow surface.

\subsection{Comparison with Dendrite Growth in Ingot Cast- ing}

Due to the requirement of short solidification time during continuous casting, cooling water is used, by which the solidification rate is much higher than that during regular ingot casting process. The maximum crystal growth rate reported for an ingot is $\sim 0.4 \mathrm{~mm} / \mathrm{s},{ }^{24,25)}$ as illustrated in Table 3 and Fig. 10. However, for steel continuous casting process, the maximum dendrite growth rate can be as big as $3 \mathrm{~mm} / \mathrm{s}$ in the continuous casting mold, which is $\sim 10$ times bigger than that of regular ingot casting process. 


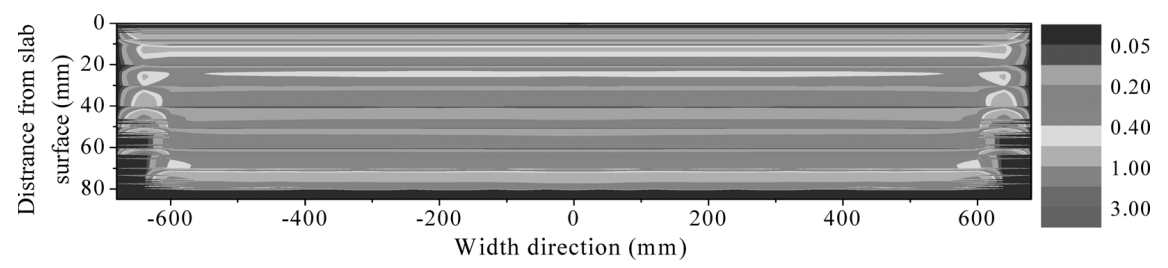

Fig. 9. Distribution of the dendrite growth rate in the slab.

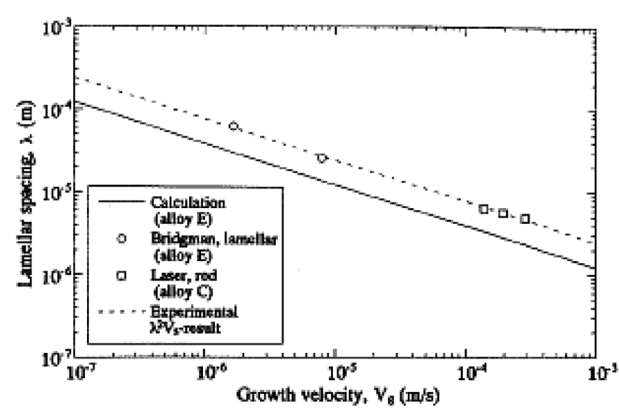

(a) Steel alloy ${ }^{24)}$

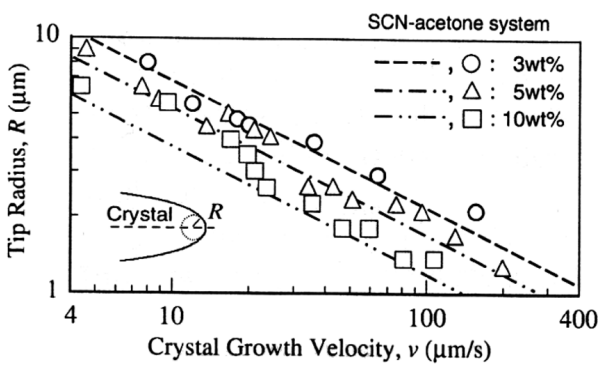

(b) SCN-acetone system ${ }^{25)}$

Fig. 10. Crystal growth rate for ingot solidification process.

Once the dendrite growth rate is calculated by the current model, the other microstructure parameters, such as secondary dendrite arm spacing, dendrite tip radius, morphology of the microstructure, and so on, can be predicted according to the models developed by the current author Zhang. ${ }^{26,27)}$

\section{Summary}

The relationship between the dendrite growth rate and the casting speed during steel continuous casting process is investigated; and a simple mathematical model is developed to calculate the primary dendrite growth rate during steel continuous casting. The dendrite growth rate in the model is described as a function of the casting speed. The dendrite growth rate of a steel slab continuous casting process is $0.1-3.0 \mathrm{~mm} / \mathrm{s}$, which agrees well with measurements. The dendrite growth rate fluctuates along casting direction because of the different cooling intensity at different zones of the continuous caster. The distribution of dendrite growth rate in the width direction is non-uniform due to the uneven transverse distribution of cooling intensity. The dendrite growth rate during continuous casting is much higher than that during regular ingot casting.

\section{Acknowledgements}

This research is supported by the Research Board Grant, Laboratory of Green Process Metallurgy and Modeling (GPMM), Materials Researcch Center (MRC) and Intelligent Systems Center (ISC) at Missouri University of Science and Technology (Missouri S\&T).

\section{REFERENCES}

1) J. M. Cabrera-Marrero, V. Carreno-Galindo, R. D. Morales and F. Chavez-Alcala: ISIJ Int., 38 (1998), No. 8, 812.

2) T. Kraft, M. Rettenmayr and H. E. Exner: Prog. Mater. Sci., 42 (1997), No. 1-4, 277.

3) D. D. Goettsch and J. A. Dantzig: Metall. Mater. Trans. A, 25A (1994), 1062.

4) N. H. Pryds and X. Huang: Metall. Mater. Trans. A, 31A (2000), No. 12,3155 .

5) R. Trivedi and W. Kurz: Metall. Mater. Trans. A, 21A (1990), 1311.

6) D. M. Stefanescu: ISIJ Int., 35 (1995), 637.

7) M. Imagumbai: ISIJ Int., 34 (1994), No. 12, 986.

8) F. Weinberg and B. Chalmers: Can. J. Phys., 30 (1952), 488.

9) J. W. Rutter and B. Chalmers: Can. J. Phys., 31 (1953), 15.

10) W. A. Tiller, K. A. Jacsoin, J. W. Rutter and B. Chalmers: Acta Metall., 1 (1953), 428.

11) K. Byungsoo: Ph.D. Dissertation Thesis, Pennsylvania State University, (2002).

12) T. Okane and T. Umeda: ISIJ Int., 38 (1998), No. 5, 454.

13) M. Yamazaki, Y. Natsume, H. Harada and K. Ohsasa: ISIJ Int., 46 (2006), No. 6, 903.

14) M. Imagumbai and T. Takeda: ISIJ Int., 34 (1994), No. 7, 574.

15) C. Cicutti, P. Bilmes and R. Boeri: Scr. Mater., 37 (1997), No. 5, 599.

16) M. Wolf, T. W. Clyne and W. Kurz: Contin. Cast., 9 (1997), 143.

17) S. Mazumdar and S. K. Ray: Sādhanā, 26 (2001), No. 1-2, 179.

18) M. Long, D. Chen, L. Zhang, M. Chen, W. Gao, Y. He and B. Hu: AISTech-Iron and Steel Technology Conf. Proc., 2 (2009), 673.

19) M. Long, D. Chen and X. Jin: J. Iron Steel Res. Int., 15 (2008), 589.

20) S. Louhenkilpi, J. Miettinen and L. Holappa: ISIJ Int., 46 (2006), No. 6, 914.

21) M. Réger and S. Louhenkilpi: Mater. Sci. Forum, 414-415 (2003), 461.

22) W. Kurz: Ia Metallurgia Italiana, (2008), 56.

23) H. Jacobi and K. Wunnenberg: Steel Res., 70 (1999), No. 8-9, 362.

24) S. Fukumoto and W. Kurz: ISIJ Int., 39 (1999), No. 12, 1270.

25) H. Yoshioka, Y. Tada and Y. Hayashi: Acta Mater, 52 (2004), 1515.

26) W. Guo, L. Zhang and M. Zhu: Steel Res. Int., 81 (2010), 265.

27) L. Zhang: AISTech-Iron and Steel Technology Conf. Proc., 2 (2010), 781 . 